\title{
Human Factor Aspects of Situation Awareness in Autonomous Cars - An Overview of Psychological Approaches
}

\section{Gábor Kovács}

Széchenyi István University, Deparment of Criminal Sciences, Egyetem tér 1, 9026 Győr, Hungary

gkovacs@sze.hu

\section{Ágnes Hőgye-Nagy, Győző Kurucz}

University of Debrecen, Institute of Psychology, Department of Social and Work Psychology, Egyetem tér 1, 4032 Debrecen, Hungary, hogye-nagy.agnes@arts.unideb.hu; kurucz.gyozo@arts.unideb.hu

Abstract: The aim of the article is to give an overview of human factor research in psychology applicable to autonomous driving. The study is centered around situation awareness, a widely used concept in human factor research regarding the operation of automated and semi-automated systems (and communication between autonomous vehicles and humans). A proposal is put forward for structuring situation awareness requirements for autonomous driving, which could be a starting point for defining such requirements, and may foster a discussion on the issues associated with the human factor in relation to autonomous driving. Two models of human error (the SHELL model and the Swiss cheese model) are also introduced, one of which represents an integrated approach of error in situations that involve humans working with complex machinery or instruments, while the other represents a more superficial viewpoint on the multicausal nature of errors. The present overview can provide an appropriate basis for a discussion about the role of the driver in autonomous vehicles, and the place of human factor research in the emerging field of self-driving technology.

Keywords: autonomous car, self-driving car, situation awareness, human factor, human error 


\section{Introduction}

Autonomous driving systems are currently one of the main research and development fields. The number of publications in this field have shown a significant increase in the last few years.

A fundamental issue, from a human factor perspective, is how to design automation so that drivers fully understand the capabilities and limitations of the vehicle, and maintain situation awareness of what the vehicle is doing and when manual intervention is needed - especially for first-generation vehicles that require drivers to resume manual control of automated functions when the vehicle is incapable of controlling itself.

However, the role of the driver, the human factor, is still underrepresented in these studies. The purpose of this paper is to document some of the human factors and challenges associated with the transition from manually driven to self-driving vehicles and to outline possibilities.

A key issue with highly automated driving (HAD) at this stage of its development is that it is not yet fully reliable and safe [1]. Therefore, in situations in which HAD fails or is limited (e.g., sensory degradation in poor weather conditions; the inability of on-board computer algorithms to make a safe decision), the driver will be expected to take control of the vehicle and resume manual driving. For this transition of control to occur safely, it is imperative that the driver fully understands the capabilities and limitations of HAD and maintains full awareness of what the vehicle is doing and when intervention might be needed [2]. In this paper, we document some of the human factor challenges associated with the transition from manually driven to self-driving vehicles.

Psychology, especially traffic psychology is a field that aims to investigate road user behavior, and the psychological aspects, factors, and processes that underlie these behaviors [3], and it should be an essential contributor to the discussion of the issues of autonomous vehicles. Still, psychological approaches are restricted mainly on questions of attitudes to and acceptance of autonomous vehicles. The nature of human cognitive processes, motivations, traits, emotions, moods, and habits all have critical effects on the driver's behavior, perception, and processing of information, which is widely investigated by psychological research. Thus, ignorance of these human characteristics might lead to potential problems and errors in the design and engineering of autonomous vehicles.

The aim of this paper is twofold. On the one hand, we would like to give an overview of the most relevant questions and results on situation awareness in the field of human factor research (see Table 1). We decided to use this expression, which is one among other often used terms in this field (e.g. human-machine interaction), since it emphasizes the place, source of problems we would like to discuss. Situation awareness has been chosen as the central focus since its role is widely accepted in the human factors literature and it is commonly applied in the 
research on human factors and on autonomous/intelligent systems. Secondly, by highlighting relevant issues and findings, this study would like to show how traffic psychology can contribute to other fields of science like engineering, information technology, and ergonomics. Hopefully, this overview will raise even more questions that need to be answered.

Table 1

Overview of problems discussed in this paper

\begin{tabular}{|c|c|c|c|c|}
\hline \multicolumn{4}{|c|}{ source of problem } & output \\
\hline \multirow{5}{*}{ 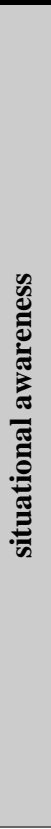 } & attention & \multicolumn{2}{|c|}{$\begin{array}{l}\text { - } \quad \text { locus of attention } \\
\text { - } \quad \text { anticipation and expectations } \\
\text { - } \quad \text { divided attention } \\
\text { - } \quad \text { limitation of capacity } \\
\text { - } \quad \text { capacity of working memory }\end{array}$} & \\
\hline & vigilance & \multicolumn{2}{|c|}{$\begin{array}{l}- \text { mental load } \\
\text { - } \quad \text { tiredness } \\
\text { - } \quad \text { boredom }\end{array}$} & reaction time \\
\hline & engagement & \multicolumn{3}{|c|}{$\begin{array}{l}\text { - } \text { disengagement } \\
\text { - } \text { distracted driving }\end{array}$} \\
\hline & $\begin{array}{l}\text { communication } \\
\text { (between } \\
\text { autonomous } \\
\text { vehicle and } \\
\text { human) }\end{array}$ & misinterpretation & & $\begin{array}{l}\text { - miscommunication } \\
\text { - effectiveness of } \\
\text { communication }\end{array}$ \\
\hline & $\begin{array}{l}\text { information } \\
\text { processing }\end{array}$ & & $\begin{array}{l}\text { - comprehension } \\
\text { problems } \\
\text { - relevance of } \\
\text { information }\end{array}$ & \\
\hline \multicolumn{2}{|c|}{ human error } & \multicolumn{3}{|c|}{$\begin{array}{l}\text { typical characteristics of human "operation" and errors } \\
\text { (concerning human-machine interaction and communication) }\end{array}$} \\
\hline
\end{tabular}

\section{The Human Factor}

The role of the human driver is extensively discussed in "traditional" driving systems. In the case of autonomous cars, the more developed the vehicle control system, the more critical the role of the human factor, - or more precisely, the change in the role of the human factor [4]. It is without question, that in the nottoo-distant future autonomous vehicles will reach, or at least will approach the level of total/full automation (level 5, defined by SAE International [5]). Misuse of equipment can cause problems even in partially automated systems [6], hence it is crucial to know if drivers are able to properly use these modern, highly automated systems. Automated systems may not be perfect, they can make wrong 
decisions and err in some situations. As humans are the only flexible, and adaptive part of the system, only they can prevent these errors by modifying the processes of the system if necessary. Carrying this out may not be easy: the operator has to know the abilities, shortcomings, and limitations of their own and those of the system. Moreover, a high level of vigilance is needed to recognize the errors or malfunctions [7]. Thus, this implies the critical issue of cognitive and other skills in the context of driving. It must be clearly seen that humans and automated systems both can make errors, which - from a psychological perspective emphasize the need for knowledge about the characteristics of human errors too.

The main subjects of human factor research are operators in nuclear power stations, oil refineries, chemical industrial plants, aviation, and autonomous vehicles. The main issues are trust, acceptance, proper use, and attention. Situation awareness seems to be an effective theoretical framework to discuss these because all of these issues can be built around this concept based on their effect on it.

\section{Situation Awareness}

Situation awareness is "the perception of the elements in the environment within a volume of time and space, the comprehension of their meaning, and the projection of their status in the near future" ([8], p. 36). It is the mental representation of the current state of the environment, more precisely that of its goal-relevant aspects. Okray and Lubnau [9] define it as a skill to become aware of the relevant, crucial characteristics of the actual situation, which is happening. It is proposed that situation awareness is the basis for decision making that involves complex and highly dynamic systems, and thus it is indispensable in fields like aviation, power plant operation, military tactics, or in more everyday activities like reading or driving in traffic.

Although there are several models of situation awareness (e.g. [10], [11]), the most widely cited and perhaps the most elaborate model in the human factors literature is that of Endsley's framework model [8]. The model contains the proposed structure of situation awareness as the representation of the current state, it's role in behavior involving a complex system, as well as endogenous and exogenous factors affecting it (Figure 1). As of the structure of situation awareness it contains three levels, and is hierarchical in nature. Level 1 is the perception of the elements, their status, and attributes in the environment. Level 2 goes beyond being simply aware of these elements, it involves the comprehension of their role in a situation, recognition of patterns, and identification of significant events. Level 3 is the projection of the current state in the near future based on the knowledge of the attributes of the elements and the understanding of the situation. As we can see the higher levels are based on the lower levels, which also implies that building up situation awareness is inherently time-consuming, and it must be 
maintained continuously to accurately represent the current situation at every level. For example, in a road traffic scenario when we approach an intersection with a certain speed, we may notice another vehicle from the right, also moving at a considerable speed having the index turned on, and that there aren't any stop signs or give way signs (level 1). From these, we conclude that the vehicle is about to take a left turn and that we have to give way according to the traffic rules (level 2). We also realize that with the current speed and course the two vehicles will crash (level 3). If this representation correctly describes the situation, it can be an apt base for a decision to avoid the collision by changing the speed or course of our vehicle. Also, an inaccurate representation on either level (level 1: overlooking the other vehicle, level 2: neglecting the traffic rules that apply to the situation, level 3: wrongly predicting the route of the vehicles) could result in an accident.

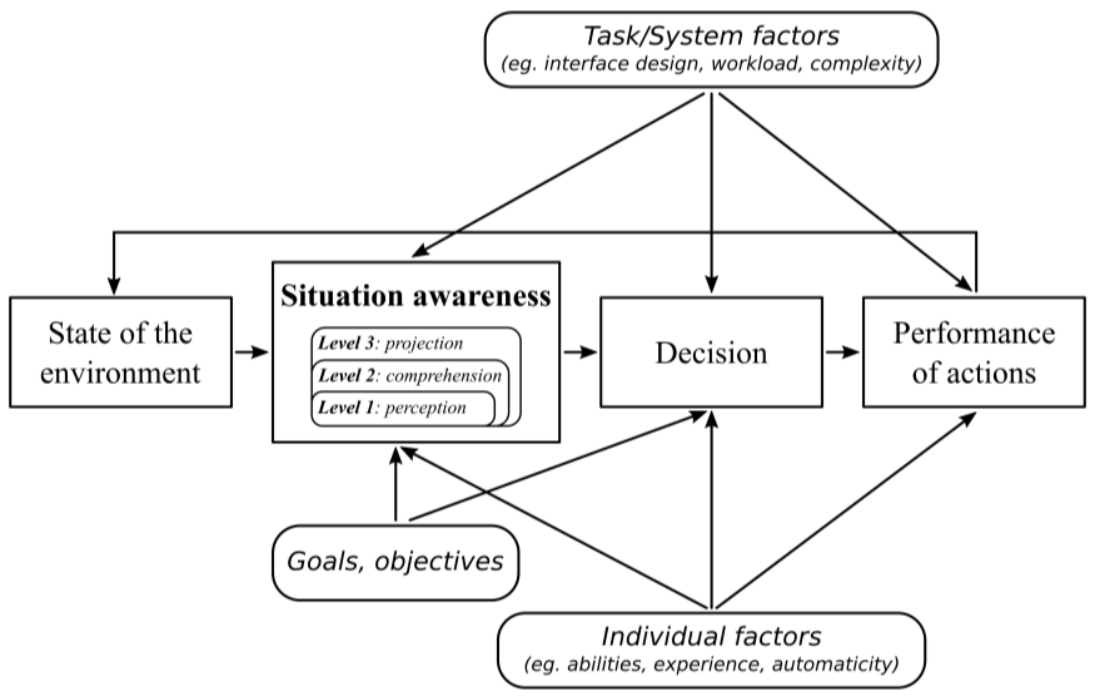

Figure 1

Endsley's framework model of situation awareness (based on [8])

It is important to note, however, that performance in a particular situation depends on situation awareness, but not identical to it. This is also emphasized by Endsley [8] or Adams et al. [12] among others. Errors can stem from an impaired assessment of the situation, from bad decision-making, or a poorly performed action. Thus, by separating the act of decision making and performance from situation awareness also makes it possible to analyze the causes of errors at a deeper level. 


\subsection{Factors Influencing Situation Awareness}

Several studies have investigated the factors which may influence situation awareness. In this section an overview is given of the most frequently cited factors based on Okray and Lubnau [9], integrating it with the most important and relevant findings in traffic psychology.

\subsubsection{Attention}

Attention is known as an effective predictor of good achievement [13] and as one of the most important factors of safe driving. Some findings suggest that over 25$50 \%$ of accidents happen because of drivers' inattention. Attention deficit might be more typical in the case of novice drivers [14], who usually tend to locate their attention ahead in a narrower scope than experienced drivers. With the advancement of driving skills, intentional control of attention becomes more effective. Driving experience is strongly connected to age: younger drivers have less experience. This must be highlighted since attitudes toward autonomous cars are more positive among the youth [15]. Attentional anticipation also improves with the familiarity of the route [16], which may result in a more goal-oriented driving, a smoother driving performance, a decrease in unnecessary declarations, and an increase in travel speed. This improvement is more significant in the case of experienced drivers.

A central characteristic of attention is a limited capacity for information processing, which can be controlled intentionally [17]. Shinoda, Hayhie, and Shrivastava [18] also emphasize the relative importance of expectations in attentional processes. While expectations in some situations are beneficial for drivers, in other situations they are proven to impair attention and perception. A driver of an autonomous car can benefit from his expectations regarding the behavior of the car - they can prepare themselves to intervene. On the other hand, in the absence of expectations they may be surprised and take desperate and improper actions if the car is perceived to act inappropriately.

Since it is impossible to attend to every aspect of the actual situation, effective direction and allocation of attention are crucial for drivers. The direction of attention is determined by both exogenous and endogenous factors [19]. For instance, a change in the environment, like a sudden movement or appearance of a new stimulus usually draws attention to itself. Although this is an unintended process, attention can be directed intentionally too. During driving there is a complex interaction between exogenous and endogenous factors, and it is crucial for the driver to detect all the relevant cues. Unnecessary distractions could impair driving performance; thus, this should be an important aspect in information systems in autonomous vehicles. Insufficient information impairs driver's situation awareness, preventing them from forming an apt picture of the actual situation and therefore inhibits adequate decision making. On the other hand, too much information overloads the cognitive system, making it harder for the driver 
to attend to the relevant aspects of the situation, also impairing situation awareness and decision making.

Divided attention enables the individual to monitor several events, several aspects of the situation at the same time. According to the early selection theory of attention [20], filtering takes place at an early stage of perception, which means that attention sharing is not possible. We can talk only about quasi-shared attention: the perceiver focuses on only a single aspect of an event at a time, but the focus is (re)directed quickly and often to another aspect, so steps of information processing happen in sequence, shortly after each other. Other theories (e.g., Kahnemann [21]) suppose that there are situations when real, parallel information processing takes place, however, it is a function of attentional capacity and attentional processing if this can happen. Enough attentional capacity enables parallel processes, otherwise, sequential processing occurs.

When talking about attention, working memory must also be mentioned as an important factor in situation awareness. Working memory enables us to remember relevant aspects of a situation and make it available for the human cognitive system. Without this attention is unfocused, and it is not targeted [22]. In an (autonomous) driving task McCarty et al. [23] found that individuals with lower working memory capacity reacted slower. This approves he suggestion that working memory also plays a critical role in safety of autonomous cars.

\subsubsection{Communication and Information Processing}

Recently communication within the framework of situation awareness has mainly focused on human-human communication in relation to teamwork, not human machines. The findings showed that communication failures may end up in serious errors and even accidents [24]. Miscommunication is more frequent in highworkload situations, e.g., in air traffic control when the pilot is not a native English speaker. This type of communication failure is less important in our current focus. We would rather highlight how human drivers may misinterpret the information perceived in direct communication between autonomous vehicles and humans.

Drivers' performance varies during information processing. Shinar et al. [25] provide a cross-national study on traffic sign symbol comprehension. They concluded that a good sign design should follow stereotypes (for example red is connected to danger), differing shapes of signs help us to distinguish among different types of messages (prohibition, warning or guiding). Relevancy is also important: relevant signs require easier recognition. There are some characteristics of traffic signs that help the recognition [26] like familiarity, concreteness, complexity, meaningfulness, and semantic difference. These findings could be important in intelligent vehicle design too since these can help human drivers' understanding of the system processes. 
In case of autonomous systems, it is crucial that the system communicates in a way that helps the drivers' information processing. Potential candidates to deal with these kinds of problems would be cognitive info-communication (CogInfoCom) [27], distributed cognition [28], or the field of human-computer interaction [29]. These multidisciplinary fields could provide recommendations regarding e.g., the type and modality of information the system provides for the user. In the case of autonomous cars, such an approach will be especially important, as the car sometimes has to effectively communicate complex representations of the system state to the driver.

\subsubsection{Boredom and Engagement: Maintaining Vigilance}

Autonomous driving systems aim to lower human mental load in order to optimize human performance. However, this approach is contradictory since the decreased mental load can cause passive tiredness and lower vigilance, which impairs attention and in a critical situation it may lead to wrong decisions. Also, drivers tend to prevent boredom, so in low-activity situations, they engage in non-driving activities behind the wheel (e.g. [30]), which is a problem because distracted driving causes higher reaction times in task-shift situations.

Reaction time is closely related to vigilance. Scientists usually treat it as a constant skill, though it is affected by several factors, like age, gender, and the actual mental state of the individual, among others. Reaction time tends to decrease with age, [13], [31]. Drivers under 30 have the lowest reaction times, and drivers above 60 the highest. These differences are enhanced by mental load [31]. Men react faster than women at any age [32]. In simulation research it was found that reaction time is also connected to human circadian rhythm and level of arousal: one tends to respond slower at $6 \mathrm{am}, 2 \mathrm{pm}$. and $2 \mathrm{am}$, than at $10 \mathrm{am}, 6 \mathrm{pm}$ or 10 pm [33].

From the results of research in the fields of aviation and air traffic control, it is known that high level of automation can contribute to boredom [34]. Boredom can lead to distraction, higher reaction times, and even more mistakes [35] however this effect isn't specifically tied to autonomous vehicles. For example, Dahlen et al. [36] found that boredom proneness can predict unsafe driving. Cummings et al. [34] concluded that subjects during a simulation of an unmanned vehicle's supervisory control spent a lot of time being distracted, and they noted that the problem can be mitigated by efficiently switching attention. Driver boredom also shows connections with personality; a higher level of enthusiasm is associated with a lower level of boredom [35], while neuroticism seems to be positively correlated with boredom. Age also seems to have an effect on boredom: younger drivers experience boredom more often than older drivers [37]. It can be an aim of design to reduce boredom; for example, Steinberger [38] has found that gamification might be a key to solve this problem. 


\subsection{Situation Awareness Requirements for Driving}

There are areas such as air-to-air combat fighters [39], infantry platoon leaders [40] or air traffic control personnel [41] where we can find information requirements for situation awareness. In the case of driving this research is at best in its infancy (see [42] for an example). However, the basis for this research in the form of descriptive driving models is very promising (see [43], [44]).

This study tries to add to this endeavor with a proposal regarding the structure of such requirements, which is also applicable to autonomous cars. At the core of this proposition is a sharp distinction between traditional driving tasks (e.g., choice of speed, steering, navigation, and monitoring of the traffic) and system-monitoring tasks (e.g., supervision of the decision of vehicles, or checking of operational conditions) of the driver. The relevance of these tasks is a function of the level of automation. Viewed simply the relevance of traditional driving tasks is higher at the lower levels of automation, while the relevance of system-monitoring tasks may be (but is not necessarily) higher at the higher levels of automation. To demonstrate this point recommendations for the levels of automation for onroad motor vehicles by the Society of Automotive Engineers [5] are used to take a look at the role of traditional driving tasks and of system monitoring tasks during driving at different levels of automation. The attentional demands and risk of boredom are also taken into consideration. These are overviewed in Figure 2.

The SAE recommendation proposes six levels of automation, ranging from level 0 (no automation) to level 5 (full automation). The difference of the levels can be easily grasped by stating who is responsible for performing the dynamic driving task (DDT) at different levels. The DDT contains essentially what Michon [43] defined as tactical and operational levels of driving tasks, and incorporates object and event detection and response (OEDR, monitoring of the driving environment), which is highly dependent on situation awareness.

At level 0 there is no automation, the driver is responsible for the whole DDT, however some vehicle systems may provide warnings or support, such as momentary emergency intervention. The role of traditional driving tasks are essential, while there is no need for monitoring of the system's state thus there isn't an increased need for the sharing of attention between these two. However, the driver needs to be receptive to the signals of the aforementioned vehicle systems. The driver needs to actively sustain their attention, and actively manage the DDT while they continuously receive feedback of their actions, so the risk of boredom is low.

Level 1 automation incorporates several driving assistant systems which manage parts of the DDT, such as lateral control of the vehicle (e.g., lane centering assist systems), or the longitudinal control of the vehicle (e.g., adaptive cruise control systems). The role of traditional driving tasks may be similarly crucial as at level 0 , as these driving assistant systems are not able to manage the full operative control of the vehicle. The driver has to monitor the functioning of the driving 
assistant system, and intervene, if necessary, hence the role of system monitoring tasks is more important, and there is a need to share attentional capacity between the two tasks. The driver needs to stay ready to take over the full DDT. The risk of boredom is low because of the highly active role in the DDT, and the need for continuous monitoring of the traffic situation.

A car with level 2 automation manages part of the DDT, both the lateral and longitudinal control of the vehicle (i.e., the operative driving tasks). The driver manages the rest of the DDT, that is the tactical driving tasks, like selecting the correct maneuver for the current situation. System monitoring tasks are more important than on the previous level, the driver has to supervise many aspects of the system. Because of the relatively low-level of activity, the risk of boredom is higher than before.

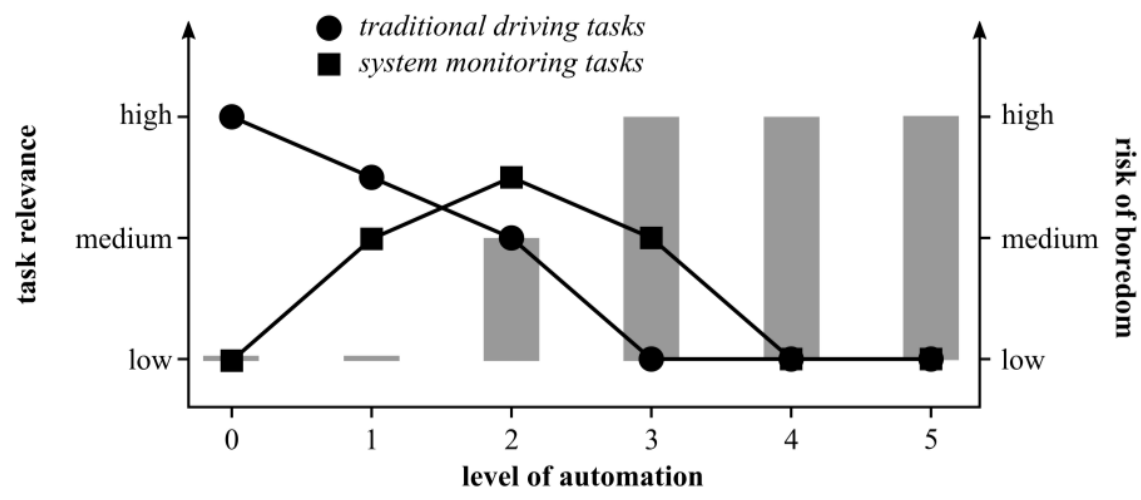

Figure 2

Supposed relevance of traditional driving tasks and system monitoring tasks and risk of boredom at different levels of automation

On level 3 the system manages the entire DDT, including the operative and tactical driving tasks. Besides these, it also monitors itself, is able to detect system malfunctions, and leaving of the operational domain. The driver does not practice any of the traditional driving tasks, and system monitoring tasks, however, all these tasks will be crucial if the driver has to take over the DDT (based on their own decision or because of system failure). Sharing of attention is not needed under normal circumstances, but in the case of takeover, there is an increased need for attention sharing. The risk of boredom is high in such scenarios, which is exceptionally dangerous if the driver needs to take over the full control of the vehicle.

Level 4 and level 5 are covered together. These are similar in that the vehicle at these levels deals with the full DDT, and is capable of performing fallback functions, or achieving minimal risk conditions in case of emergency, or if it leaves its operational domain. The main difference between these two levels is the range of situations it can handle, that is the broadness of their operational 
domains. As the driver does not have to do traditional driving tasks or system monitoring tasks, shared attention is not needed, but the risk of boredom is high. However, as the system is capable of intervention, and bringing the vehicle to safety, boredom should not be a cause of problem even in emergency situations.

Naturally, requirements regarding specific traditional driving tasks and system monitoring tasks can be distinct in different traffic scenarios and can vary depending on the system implementation at hand. These specific information must surely be taken into consideration when specifying the exact SA requirements.

\section{Understanding Human Error: SHELL and Swiss Cheese Model}

Technical development has solved numerous problems and ruled out errors in the field of traffic and transport, though the role of human error is still significant [45]. According to the findings of the International Civil Aviation Organization (ICAO), the last few decades can be described by a decreased number of machine errors and an increased number of human errors. The Civil Aviation Authority refers to Admiral Donald Engen that it is high time to focus on the human since the hardware field of traffic is quite reliable [46]. Two known and accepted frameworks of human error are to be considered: the SHELL model and the Swiss cheese model.

The conceptual framework of the SHELL model describes how humans as operators function in a complex system [46], [47], [48], [49], [50]. The model is widely used in aviation and traffic psychology and provides a framework for understanding and modeling human errors in a complex system. The original concept is introduced by Edwards [51], and modified by Hawkins [52]. The model places the human factor in the center, as it is the most crucial, yet the most flexible element of the system. The human factor is characterized by inconstant performance and limitations. This premise holds for autonomous vehicles as well since it is profoundly the driver, who monitors the functioning of the system and intervenes if necessary.

Figure 3 shows the building blocks and their connection points in the model. It is useful to notice that the edges of the blocks are irregular. It indicates that the components must be fitted carefully to the central component, aka the human component [46]. Each and every component has crucial characteristics that have to be taken into consideration when designing a system. The most important features of the liveware/human component are physical size, shape, physiological demands (food, oxygen, water, etc.), input characteristics (features of perception), characteristics of information processing, output characteristics (movement, communication), and environmental tolerances (temperature, noise, pressure, light, etc.). 


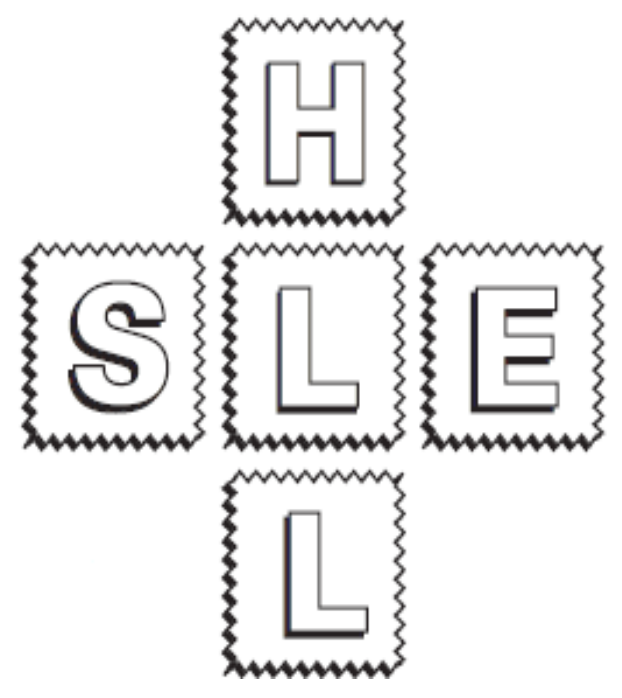

Figure 3

The building blocks of the SHELL model ([46], p. 12; S: software, H: hardware, L: liveware /human/, E: environment)

The fitting of liveware and hardware includes the aspects of human-machine interaction. Possible discrepancies are masked by human features, so problems usually emerge later in time. The liveware and environment fit was a focus of early research (e.g., protective clothing against harmful environmental effects). Lately, there are attempts to reshape the environment, so it fits the human needs (e.g., virtual functions). The liveware-liveware interaction is highly important in traffic psychology since human communication in teams and leadership are crucial in aviation. However, when dealing with autonomous vehicles it remains a question, how much importance it holds.

The liveware-software interaction means all the non-physical aspects of the system. Masking of errors might be highly critical here. The software element has an important role in the case of autonomous vehicles. Moreover, the functioning of the car and the IT system has to be extensively recognized. This means that it also has a training aspect, the driver has to study how the IT system of the vehicle works, how it decides, reacts in certain situations, and the limitations of the system have to be clear too. The system has to provide enough information to the driver in order to enable them to effectively monitor its functioning and to have a clear picture of the actual state of the system. At first glance, this seems to be easy, but it raises several questions. The information must be given "economically", it must be sufficient to gain an overview, but not too much, as it may unnecessarily increase the mental load. The timing of information is also critical, too early and too late are both problematic. For example, on motorways warnings are given earlier that is traffic signs are further away from the related elements than in a small village since at higher speeds more time may be needed to respond 
appropriately. Another question is the case of multiple warnings at the same time. Will, it mentally overload the driver, and if so, how much will it increase reaction times?

A new aspect emerges in the case of autonomous cars, namely software-software interaction that is when the different systems communicate with each other. However, the question of this kind of communication is outside the reach of human factor research.

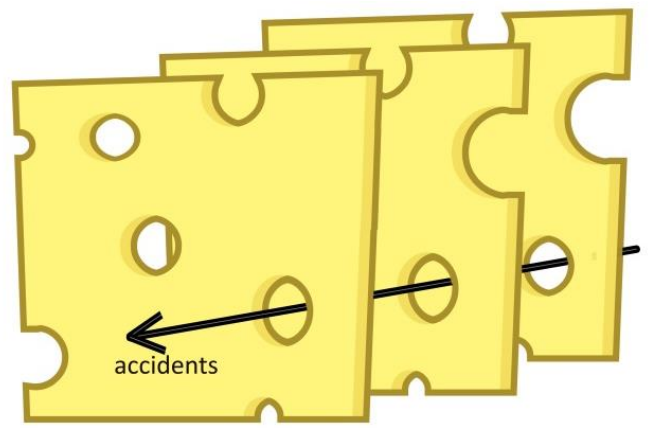

Figure 4

Swiss cheese model of errors

The Swiss cheese model introduced by Reason [53] sets the different levels/layers of prevention in focus (Figure 4). In an organization (e.g. aviation), and even in engineering, there are many types of defense in order to avoid accidents. These are represented by the layers (layered security). The holes on the layers represent both active failures and latent conditions (e.g. engineering, mechanical, control, maintenance, or application problems). The model proposes that accidents happen when these active failures and/or latent conditions coincide. It also illustrates how a potential accident can get through a safety system and how multicausal it can be.

\section{Conclusions}

In this paper, several psychological findings have been reviewed together with the role of the human factor in autonomous vehicles. Situation awareness was used as a central concept to guide the review. It is argued that during the design and engineering of autonomous vehicles the models and empirical findings of such research could be beneficial, and using this knowledge would help in constructing autonomous cars that are more user friendly and safer. A structure has also been proposed for situation awareness requirements that are applicable to traditional driving as well as to driving of autonomous vehicles. Having observed the abilities and limitations of human drivers regarding the operation of a self-driving vehicle, the legal aspects of autonomous driving should be considered. With this review, we hope to stimulate discussions on human factor issues amongst more technical approaches to autonomous vehicles since it is obvious that humans will play an integral part in this complex system in the foreseeable future. 


\section{Acknowledgement}

This work has been funded by the European Union through the project titled "Felsőoktatási és Ipari Együttműködési Központ a Széchenyi István Egyetemen" (GINOP-2.3.4-15-2016-00003).

\section{References}

[1] M. Martens and A. van den Beukel, The road to automated driving: Dual mode and human factors considerations. 2013

[2] M. L. Cummings and J. Ryan, "Who is in charge?: The promises and pitfalls of driverless cars," TR News, pp. 25-30, 2014

[3] T. Rothengatter, "Psychological Aspects of Road User Behaviour," Applied Psychology, Vol. 46, No. 3, pp. 223-234, 1997, doi: https://doi.org/10.1111/j.1464-0597.1997.tb01227.x

[4] M. Kyriakidis et al., "A human factors perspective on automated driving," Theoretical Issues in Ergonomics Science, Vol. 20, No. 3, pp. 223-249, May 2019, doi: 10.1080/1463922X.2017.1293187

[5] SAE International, "J3016B: Taxonomy and Definitions for Terms Related to Driving Automation Systems for On-Road Motor Vehicles," 2018 [Online] Available: https://www.sae.org/standards/content/j3016_201806/

[6] A.-M. Feyer, A. M. Williamson, and D. R. Cairns, "The involvement of human behaviour in occupational accidents: Errors in context," Safety Science, Vol. 25, No. 1, pp. 55-65, 1997, doi: 10.1016/S09257535(97)00008-8

[7] M. Cunningham and M. A. Regan, “Autonomous Vehicles: Human Factors Issues and Future Research,” p. 12, 2015

[8] M. R. Endsley, "Toward a Theory of Situation Awareness in Dynamic Systems," Hum Factors, Vol. 37, No. 1, pp. 32-64, Mar. 1995, doi: 10.1518/001872095779049543

[9] R. Okray and T. Lubnau, Crew Resource Management for the Fire Service, $50125^{\text {th }}$ edition, Tulsa, Okla: Fire Engineering Books \& Videos, 2003

[10] F. T. Durso and A. Sethumadhavan, "Situation awareness: understanding dynamic environments," Hum Factors, Vol. 50, No. 3, pp. 442-448, Jun. 2008, doi: 10.1518/001872008X288448

[11] K. Smith and P. A. Hancock, "Situation Awareness Is Adaptive, Externally Directed Consciousness:," Human Factors, 1995, doi: 10.1518/001872095779049444

[12] M. J. Adams, Y. J. Tenney, R. W. Pew, Y. J. Tenney, and R. W. Pew, "Situation Awareness and the Cognitive Management of Complex Systems," Situational Awareness, Jul. 2017, doi: 10.4324/97813150879244 
[13] J. A. Groeger, Understanding driving: Applying cognitive psychology to a complex everyday task. New York, NY, US: Psychology Press, 2000

[14] G. Underwood, "Visual attention and the transition from novice to advanced driver," Ergonomics, Vol. 50, No. 8, pp. 1235-1249, 2007, doi: 10.1080/00140130701318707

[15] L. M. Hulse, H. Xie, and E. R. Galea, "Perceptions of autonomous vehicles: Relationships with road users, risk, gender and age," Safety Science, Vol. 102, pp. 1-13, 2018, doi: 10.1016/j.ssci.2017.10.001

[16] K. J, N. V-M, K. K, and J. T, "Driving Characteristics and Development of Anticipation of Experienced and Inexperienced Drivers When Learning a Route in a Driving Simulator," Paris, France, 2012, p. 5

[17] E. A. Styles, The psychology of attention, $2^{\text {nd }} e d$. New York, NY, US: Psychology Press, 2006

[18] H. Shinoda, M. M. Hayhoe, and A. Shrivastava, "What controls attention in natural environments?," Vision Research, Vol. 41, No. 25-26, pp. 35353545, 2001, doi: 10.1016/S0042-6989(01)00199-7

[19] G. J. Hole, The Psychology of Driving, $1^{\text {st }}$ ed. Mahwah, NJ: Routledge, 2006

[20] D. E. Broadbent, Perception and communication. Elmsford, NY, US: Pergamon Press, 1958

[21] D. Kahneman, Attention and effort. Englewood Cliffs N.J.: Prentice-Hall, 1973

[22] J. Wiley and A. F. Jarosz, "Working memory capacity, attentional focus, and problem solving," Current Directions in Psychological Science, Vol. 21, No. 4, pp. 258-262, 2012, doi: 10.1177/0963721412447622

[23] M. McCarty, K. Funkhouser, J. Zadra, and F. Drews, "Effects of Auditory Working Memory Tasks while Switching between Autonomous and Manual Driving," Proceedings of the Human Factors and Ergonomics Society Annual Meeting, Vol. 60, No. 1, pp. 1741-1745, Sep. 2016, doi: $10.1177 / 1541931213601399$

[24] B. R. C. Molesworth and D. Estival, "Miscommunication in general aviation: The influence of external factors on communication errors," Safety Science, Vol. 73, pp. 73-79, Mar. 2015, doi: 10.1016/j.ssci.2014.11.004

[25] D. Shinar, R. Dewar, H. Summala, and L. Zakowska, "Traffic sign symbol comprehension: a cross-cultural study," Ergonomics, Vol. 46, No. 15, pp. 1549-1565, 2003, doi: 10.1080/0014013032000121615

[26] S. J. P. McDougall, M. B. Curry, and O. de Bruijn, "Measuring symbol and icon characteristics: Norms for concreteness, complexity, meaningfulness, 
familiarity, and semantic distance for 239 symbols," Behavior Research Methods, Instruments \& Computers, Vol. 31, No. 3, pp. 487-519, 1999, doi: 10.3758/BF03200730

[27] P. Baranyi, A. Csapo, and G. Sallai, Cognitive Infocommunications (CogInfoCom) Springer International Publishing, 2015

[28] J. Hollan, E. Hutchins, and D. Kirsh, "Distributed Cognition: Toward a New Foundation for Human-computer Interaction Research," ACM Trans. Comput.-Hum. Interact., Vol. 7, No. 2, pp. 174-196, Jun. 2000, doi: $10.1145 / 353485.353487$

[29] J. Preece, Y. Rogers, H. Sharp, D. Benyon, S. Holland, and T. Carey, Human-Computer Interaction. GBR: Addison-Wesley Longman Ltd., 1994

[30] H. Clark and J. Feng, "Age differences in the takeover of vehicle control and engagement in non-driving-related activities in simulated driving with conditional automation," Accident Analysis \& Prevention, Vol. 106, pp. 468-479, Sep. 2017, doi: 10.1016/j.aap.2016.08.027

[31] H. Makishita and K. Matsunaga, "Differences of drivers' reaction times according to age and mental workload," Accid Anal Prev, Vol. 40, No. 2, pp. 567-575, Mar. 2008, doi: 10.1016/j.aap.2007.08.012

[32] L. Warshawsky-Livne and D. Shinar, "Effects of uncertainty, transmission type, driver age and gender on brake reaction and movement time," Journal of Safety Research, Vol. 33, No. 1, pp. 117-128, 2002, doi: 10.1016/S00224375(02)00006-3

[33] M. G. Lenné, T. J. Triggs, and J. R. Redman, "Time of day variations in driving performance," Accid Anal Prev, Vol. 29, No. 4, pp. 431-437, Jul. 1997, doi: 10.1016/s0001-4575(97)00022-5

[34] M. L. Cummings, C. Mastracchio, K. M. Thornburg, and A. Mkrtchyan, "Boredom and Distraction in Multiple Unmanned Vehicle Supervisory Control," 2013, Accessed: Jul. 22, 2020 [Online] Available: https://dspace.mit.edu/handle/1721.1/86942

[35] S. Heslop, "Driver boredom: Its individual difference predictors and behavioural effects," Transportation Research Part F: Traffic Psychology and Behaviour, Vol. 22, pp. 159-169, 2014, doi: 10.1016/j.trf.2013.12.004

[36] E. R. Dahlen, R. C. Martin, K. Ragan, and M. M. Kuhlman, "Boredom proneness in anger and aggression: Effects of impulsiveness and sensation seeking," Personality and Individual Differences, Vol. 37, No. 8, pp. 16151627, 2004, doi: 10.1016/j.paid.2004.02.016

[37] J. Harvey, S. Heslop, and N. Thorpe, "The categorisation of drivers in relation to boredom," Transportation Planning and Technology TRANSPORT PLANNING TECHNOL, Vol. 34, pp. 51-69, 2011, doi: 10.1080/03081060.2011.530829 
[38] F. Steinberger, R. Schroeter, and C. Watling, "From Road Distraction to Safe Driving: Evaluating the Effects of Boredom and Gamification on Driving Behaviour, Physiological Arousal, and Subjective Experience," Computers in Human Behavior, Vol. 75, Jun. 2017, doi: 10.1016/j.chb.2017.06.019

[39] M. R. Endsley, "A survey of situation awareness requirements in air-to-air combat fighters," The International Journal of Aviation Psychology, Vol. 3, No. 2, pp. 157-168, 1993, doi: 10.1207/s15327108ijap0302_5

[40] M. Matthews, L. Strater, and M. Endsley, "Situation Awareness Requirements for Infantry Platoon Leaders.," Military Psychology, Vol. 16, pp. 149-161, Jul. 2004, doi: 10.1207/s15327876mp1603_1

[41] M. R. Endsley and M. D. Rodgers, "Situation Awareness Information Requirements Analysis for En Route Air Traffic Control:," Proceedings of the Human Factors and Ergonomics Society Annual Meeting, 1994, doi: $10.1177 / 154193129403800113$

[42] M. Matthews, D. Bryant, R. Webb, and J. Harbluk, "Model for Situation Awareness and Driving: Application to Analysis and Research for Intelligent Transportation Systems," Transportation Research Record, Vol. 1779, pp. 26-32, 2001, doi: 10.3141/1779-04

[43] J. A. Michon, "A Critical View of Driver Behavior Models: What Do We Know, What Should We Do?," in Human Behavior and Traffic Safety, L. Evans and R. C. Schwing, Eds. Boston, MA: Springer US, 1985, pp. 485524

[44] A. J. McKnight and B. B. Adams, "Driver Education Task Analysis. Volume I: Task Descriptions. Final Report (August 1969-July 1970),” Nov. 1970, Accessed: Jul. 23, 2020 [Online]

[45] A. Hobbs, "Human Factors: The Last Frontier of Aviation Safety?," International Journal of Aviation Psychology - INT J AVIAT PSYCHOL, Vol. 14, pp. 331-345, Oct. 2004, doi: 10.1207/s15327108ijap1404_1

[46] CAA, Civil Aviation Authority, Safety Regulation Group, and International Civil Aviation Organization, Fundamental human factors concepts: (previously ICAO digest No. 1) West Sussex, UK: Civil Aviation Authority, 2002

[47] M. Martinussen, D. R. Hunter, and D. R. Hunter, Aviation Psychology and Human Factors. CRC Press, 2017

[48] G. Molloy and C. A. O'Boyle, “The SHEL Model: A Useful Tool for Analyzing and Teaching the Contribution of Human Factors to Medical Error," Acad.Med., Vol. 80, No. 2, pp. 152-155, 2005, doi: 10.1097/00001888-200502000-00009 
[49] D. A. Wiegmann and S. A. Shappell, "Human error perspectives in aviation," The International Journal of Aviation Psychology, Vol. 11, No. 4, pp. 341-357, 2001, doi: 10.1207/S15327108IJAP1104_2

[50] D. A. Wiegmann, S. A. Shappell, and S. A. Shappell, A Human Error Approach to Aviation Accident Analysis : The Human Factors Analysis and Classification System. Routledge, 2003

[51] E. Edwards, "Man and Machine: Systems for Safety," in Proceedings of British Airline Pilots Association Technical Symposium, London, 1972, pp. 21-36

[52] F. H. Hawkins, Human Factors in Flight. Routledge, 2017

[53] J. Reason, Human Error. Cambridge: Cambridge University Press, 1990 